Mens

revue d'histoire intellectuelle de l'Amérique française

\title{
Alexandre Stefanescu (dir.). René Lévesque : mythes et réalités, Montréal, VLB éditeur, 2008, 249 p.
}

\section{Mathieu Bock-Côté}

Volume 10, numéro 2, printemps 2010

URI : https://id.erudit.org/iderudit/1023309ar

DOI : https://doi.org/10.7202/1023309ar

Aller au sommaire du numéro

Éditeur(s)

Centre de recherche en civilisation canadienne-française

ISSN

1492-8647 (imprimé)

1927-9299 (numérique)

Découvrir la revue

Citer ce compte rendu

Bock-Côté, M. (2010). Compte rendu de [Alexandre Stefanescu (dir.). René

Lévesque : mythes et réalités, Montréal, VLB éditeur, 2008, 249 p.] Mens, 10(2),

99-103. https://doi.org/10.7202/1023309ar 


\section{Comptes rendus}

\section{Alexandre Stefanescu (dir.). RenéLévesque: mythes et réalités, Montréal, VLB éditeur, 2008, 249 p.}

Ce collectif, sous la direction d'Alexandre Stefanescu, est tiré d'un colloque tenu à l'automne 2007 à la Grande Bibliothèque sous l'autorité de la Fondation René-Lévesque, qui entendait faire un bilan des connaissances et des interprétations disponibles sur René Lévesque. Devenu mythe national de son vivant et consacré dans cette fonction les jours qui ont suivi son décès, René Lévesque occupe à lui seul le panthéon des héros du Québec moderne, à la manière du père fondateur d'un pays longtemps imaginé et toujours imaginaire. Mis à part la monumentale biographie que lui a consacrée Pierre Godin et l'essai que lui a récemment consacré Martine Tremblay, Derrière les portes closes, en plus d'un collectif paru au début des années 1990, enregistrant quelques années après sa mort son empreinte sur la société québécoise, et des quelques essais critiques qui ont jalonné sa carrière politique, on trouve peu de sources valables sur Lévesque, et encore moins sur son œuvre. Ce livre est pour cela plus que le bienvenu et contribue à un renouvellement des perspectives sur le travail d'un homme qui aura laissé, comme le veut la formule, une empreinte définitive dans la conscience nationale.

Le livre contient plusieurs contributions. C'est la loi du genre, certaines sont de grande valeur, d'autres meublent les pages. Mais les bons textes contribuent néanmoins à de véritables ouvertures historiographiques vers le chantier de l'histoire du souverainisme dans la perspective non plus seulement d'une histoire de la modernité québécoise, mais aussi d'une histoire de la question nationale. Ces bons textes s'interrogent sur le rapport de René Lévesque au conservatisme québécois et au traditionalisme canadien-français. Apports indispensables dans la mesure où ils relativisent le grand récit de la modernité québécoise, fondé sur la disqualification puis l'abolition 
de l'expérience historique canadienne-française. On connaît la légende dorée de la Révolution tranquille, celle d'une société qui aurait fait sa révolution contre elle-même et se serait désentravée de ce qui, dans sa condition historique, aurait contribué à son aliénation. Les meilleurs chercheurs québécois s'interrogent désormais sur ce grand récit qui n'en finit plus de célébrer la réussite d'une société qui se disloque.

C'est Xavier Gélinas qui pose d'abord la question du rapport entre Lionel Groulx et René Lévesque. On le sait, selon le discours officiel, le grand historien et le père fondateur du Québec moderne n'auraient rien en commun. D'usage, les deux figures sont présentées comme radicalement contradictoires. On imagine bien mal un leader souverainiste se réclamer aujourd'hui de la mémoire de Lionel Groulx, sinon pour dire que le Québec contemporain n'est plus du tout le sien. Il faudrait absolument imperméabiliser le souverainisme moderne contre le nationalisme historique tel qu'il s'est reconstitué en mouvement autour des années 1920, justement grâce à l'action de Lionel Groulx. Xavier Gélinas, qui avait déjà contribué massivement au renouvellement de l'historiographie intellectuelle québécoise avec son ouvrage consacré à la droite intellectuelle au moment de la Révolution tranquille, démontre qu'il n'en est rien. Entre le nationalisme de Groulx et celui de Lévesque, il ne manquerait pas de continuités. Sur le plan du statut politique, de la définition de la nation, du rôle de l'État, mais aussi de l'éducation et de la culture, les deux hommes se répondaient implicitement à une génération de distance. Gélinas suggère même que le rapport de Lévesque à Groulx devrait être pensé à partir du rapport de ce dernier avec Henri Bourassa qui, en son temps aussi, fixa une définition forte de la nation canadienne-française en plus d'établir un cadre stratégique pour assurer sa promotion. Gélinas reconnaît évidemment que les successeurs de Lévesque ont rétrospectivement construit l'image d'un père fondateur du souverainisme moderniste, qui aurait affranchi le Québec de son passé. Il invite néanmoins les historiens à ne pas se laisser envoûter par ce récit afin de mieux saisir la nature de la métamorphose du nationalisme québécois, au moment de sa modernisation. Il n'est 
pas interdit de penser que Gélinas suggère aussi aux nationalistes québécois de proposer pour eux-mêmes un autre récit des origines, qui permettrait de se déprendre de la mémoire en cul-de-sac de ce qu'est devenu le souvenir de la Révolution tranquille.

Sur un même registre, Éric Bédard s'intéresse à l'alliance de René Lévesque avec les bleus, ces nationalistes plus conservateurs, attachés au Québec traditionnel, qu'il préférait grandement aux indépendantistes socialisants du Rassemblement pour l'indépendance nationale (RIN). Loin de diaboliser le conservatisme ordinaire de ces notables de province ralliés à la souveraineté, René Lévesque croyait nécessaire de s'allier avec lui pour "déradicaliser " l'idéal de l'indépendance et le raccrocher à ceux qui ne s'enthousiasmaient pas outre mesure pour la technomodernité québécoise qui se mettait en place. À travers le Parti québécois, c'est une nouvelle synthèse du nationalisme qui se formulait en faisant sa place au Québec traditionnel, non seulement sur le plan des objectifs politiques, mais aussi dans le réaménagement de la conscience historique afin d'éviter que l'identité québécoise ne prenne le pli intégral de la rupture sur le modèle des théories de la décolonisation que proposaient les militants du RIN. Éric Bédard, qui ne fait pas mystère de son conservatisme, entend probablement, dans cette contribution, réhabiliter la synthèse nationaliste réalisée par René Lévesque, qui ne penchait pas qu'à gauche, et dont la remise à neuf permettrait au souverainisme de se recomposer à partir d'une autre matrice que celle qui fut la sienne depuis quelques années.

Ces deux contributions, certainement les plus fortes de l'ouvrage, trouvent un écho indirect dans plusieurs autres textes, ceux d'Alain Noël, de Marc Comby et de Serge Denis, qui, inversement, s'interrogent sur le rapport de René Lévesque avec la gauche, une question symptomatique, certainement, d'une génération d'intellectuels déçus de ne pas avoir trouvé dans le souverainisme le véhicule vers un socialisme à la québécoise. Étrange déception, car si le Parti québécois n'a pas su réaliser l'indépendance, il aura mené à terme la reprogrammation progressiste de la société québécoise. Lévesque était-il vraiment de gauche? Autrement dit, était-il dans le camp du bien? Il en ressort 
néanmoins, malgré les commentaires rassurants d'Alain Noël, qui semble bien se demander comment il pourrait admirer un homme qui ne serait pas associé pour de bon à la gauche, que René Lévesque, qui détestait plus que tout le radicalisme idéologique, a fait problème pour le socialisme de l'intelligentsia. À la différence des hommes de gauche, René Lévesque ne se demandait pas systématiquement ce qu'était la gauche et ce qu'elle devait devenir. Il se demandait encore moins ce qu'elle était " vraiment ". Il ne se reconnaissait pas non plus dans les entreprises théoriques, si fréquentes dans les années 1970, cherchant toujours à refonder la société à partir d'une modélisation du socialisme idéal. C'est probablement Jean-Jacques Simard, dans une contribution touffue et un peu brouillonne, qui donne néanmoins la définition la plus juste de Lévesque, en le décrivant à la fois comme un vieux libéral à l'américaine et comme un technocrate populiste, attentif à la science moderne du gouvernement mais réfractaire à la prétention des bureaucrates à planifier toute la société.

L'œuvre de Lévesque, aussi imposante soit-elle, fait souvent écran à la réalité de son indéniable échec du projet politique auquel il est pourtant associé dans la conscience collective. Daniel Jacques le souligne dans sa contribution à l'ouvrage : René Lévesque a entrâné le Québec dans une spirale régressive, d'abord en perdant le référendum, puis en ne sachant pas gérer les conséquences de cette défaite. On pourrait aussi poser le problème autrement. La constante référence à Lévesque laisse croire, à ceux qui le veulent bien, que la grande tâche historique du Québec est terminée, que le Québec est désormais une société normale, appelée au gouvernement ordinaire des affaires publiques. Tous les partis se réclament du mythe Lévesque et l'instrumentalisent la plupart du temps afin de neutraliser le mouvement national, en dédramatisant les conséquences des deux référendums. Daniel Jacques invite ainsi les Québécois à se déprendre du mythe souverainiste au cœur de la fatigue politique du Québec français et à imaginer un avenir qui ne soit plus tenu à la promesse de la prochaine fois évoquée par René Lévesque en 1980. 
Mentionnons aussi que le livre contient des contributions de Louis Balthazar, qui nous rappelle les sympathies américaines bien connues de René Lévesque; de Guy Lachapelle, qui fait tout, sans surprise, pour nous convaincre de la modernité de son nationalisme; de Philip Resnick, sur le rapport qu'entretenait Lévesque avec le Canada anglais; de Pierre Anctil, sur son rapport avec les « communautés culturelles »; et de Pierre Nepveu, sur la littérature et René Lévesque dans un texte ésotérique qui n'a pas vraiment sa place dans un tel recueil où les contributions de bonne tenue sont plutôt la norme.

Allons à l'essentiel. On retrouve dans ce collectif un appel convaincant à rouvrir le chantier de l'histoire politique québécoise, afin de sortir de la légende dorée de la Révolution tranquille et revisiter certaines filiations inavouées dans la conscience nationale et sur le plan de nos traditions politiques. Ce bon livre dévoile surtout l'impensé progressiste du nationalisme moderne et invite les chercheurs à faire une histoire du Québec qui problématise le modernisme normalisé dans la conscience collective. Reste une conclusion, la plus importante : il faudra s'interroger sur le nationalisme québécois et ses controverses fondatrices, plus encore, sur les origines complexes du souverainisme et du Parti québécois.

\section{- Mathieu Bock-Côté \\ Département de sociologie Université du Québec à Montréal}

\section{Mathieu Houle-Courcelles. Sur les traces de l'anarchisme au Québec (1860-1960), Montréal, Lux, 2008, 275 p.}

Mathieu Houle-Courcelles nous avait habitués à la grande qualité de ses présentations de moments de l'histoire de l'anarchisme au Québec, signées sous le nom de Michel Nestor, dans les pages de 